\title{
Influence of the (citric acid/calcium) ratio on Hap particles synthesis
}

\author{
C. Santos*, M. Martins**, M. M. Almeida*, M. E. V. Costa* \\ * Department of Ceramic and Glass Engineering, CICECO, University of Aveiro, 3810-193 Aveiro, \\ Portugal \\ ** Department of Chemistry, CICECO, University of Aveiro, 3810-193 Aveiro, Portugal. \\ elisabete.costa@ua.pt
}

Calcium phosphate $(\mathrm{CaP})$ particles aimed at specific applications including dental defect filling, bone tissue engineering and drug delivery may be engineered by different methods based on solution chemical precipitation. The understanding of $\mathrm{CaP}$ particle morphology evolution during precipitation is of great scientific interest not only from a fundamental point of view but also because morphology directly or indirectly determines the applicability of the particle. Citrate ion, widely known as a minor bone component, plays an important role as crystal habit modifier and crystal growth inhibitor [1]. However the prediction of $\mathrm{CaP}$ growth morphologies in presence of citrate ion is still a challenging issue because the mechanism of citrate and $\mathrm{CaP}$ interactions is not yet clearly understood.

This work reports the influence of two experimental variables on the properties of the particles precipitated from calcium/phosphate/citric acid solutions: (i) the solution (citric acid)/ (calcium) ratio (R) and (ii) the solution $\mathrm{pH}$. For this purpose different supersaturated solutions with different $\mathrm{R}, \mathrm{R}=3$ or $\mathrm{R}=5$, and different $\mathrm{pH}$ values were prepared as follows: an aqueous citric acid solution (0.6 $\mathrm{M}$ for $\mathrm{R}=3$ or $1 \mathrm{M}$ for $\mathrm{R}=5$ ) was added with small amounts of $\mathrm{NH}_{4} \mathrm{OH}$ (25\%) for $\mathrm{pH}$ adjustment and then mixed with appropriated amounts of $\mathrm{Ca}\left(\mathrm{NO}_{3}\right)_{2}$ solutions $(0.2 \mathrm{M})$ and of $\left(\mathrm{NH}_{4}\right)_{2} \mathrm{HPO}_{4}$ solutions $(0.2 \mathrm{M})$. The resulting homogeneous calcium/citrate/phosphate solutions were transferred to a heated bath and kept at $37^{\circ} \mathrm{C}$ during 24 hours. The precipitated particles were characterized by transmission and scanning electron microscopy (TEM and SEM) for morphology evaluation, gas adsorption/desorption (BET and BJH methods) for specific surface area and pore size evaluation, Xray diffraction (XRD) for crystal phase analysis and inductively coupled plasma (ICP) for $\mathrm{Ca} / \mathrm{P}$ ratio determination.

The obtained results show that the variation of $\mathrm{R}$ in the precipitating medium enables the modification of particles characteristics: it was possible under a negligible $\mathrm{pH}$ variation to switch the precipitated particle morphology from a nanometric needle like shape to a micrometric flower like shape by increasing $\mathrm{R}$ from 3 to 5 (fig 1). Accordingly the specific surface areas of the so obtained particles were very different, increasing from $20 \mathrm{~m}^{2} / \mathrm{g}$ for micrometric particles to $170 \mathrm{~m}^{2} / \mathrm{g}$ for nanometric ones. In spite of these differences the XRD spectra of the powders precipitated from the solutions with different citrate contents (fig.2, A) reveal that both types of particles are a poorly crystallized hydroxyapatite (Hap). The FTIR of the powders (fig.2, B) confirm the existence of an apatite inorganic phase while revealing the presence of citrate species. The particles molar $\mathrm{Ca} / \mathrm{P}$ ratios were also evaluated being found similar values: 1.68 for nanometric particles $(\mathrm{R}=3)$ and 1.8 for microparticles $(\mathrm{R}=5)$. According to literature reports $\mathrm{Ca} / \mathrm{P}=1.67$ corresponds to stoichiometric hydroxyapatite. The obtained $\mathrm{Ca} / \mathrm{P}$ values indicate that $\mathrm{R}$ variations were not followed by significant $\mathrm{Ca} / \mathrm{P}$ variations. The present results also demonstrate that the $\mathrm{pH}$ value of the precipitation medium is a crucial parameter for tailoring the precipitated particle morphology too. As observed in fig.2, for the case of $\mathrm{R}=5$, the flower like shape gives place to a bundle like shape and then to a spherical like shape as $\mathrm{pH}$ suffers small increases, from $8,15 \pm 0,02$ up to $8,62 \pm 0,02$. It is here suggested that $\mathrm{pH}$ 
sensitive behaviour of particle morphology may be related with the $\mathrm{pH}$ dependence of the citrate species electrical charge and composition which in turn condition the Hap particle nucleation and growth as previously established for a solution medium with $\mathrm{R}=3$ where different morphologies were obtained too [2]. Further studies are now in progress aiming at to deepen the understanding of the observed small $\mathrm{pH}$ variations effects on the particle shape.

It is possible to conclude that the morphology of the precipitated powders is strongly dependent on the experimental conditions, particularly on the cit/Ca ratio and on the $\mathrm{pH}$ value. In spite of that the addition of different amounts of citric acid to the synthesis medium does not induce any significant change on the precipitated particle crystallinity or molar $\mathrm{Ca} / \mathrm{P}$ ratio.

\section{References}

[1] A. López-Macipe, R. Rodriguez-Clemente, J. Colloid Interface Sci. 200 (1998) 114.

[2] M.A. Martins, C.Santos, M.M Almeida, MEV Costa, J: Colloid Interface Sci. 318 (2008) 210

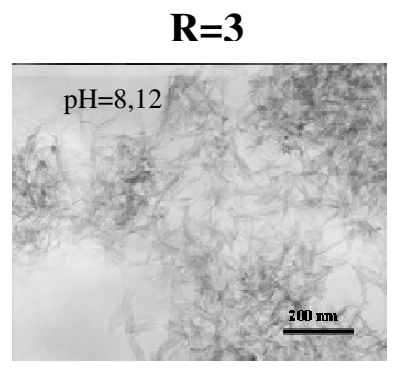

Fig. 1.TEM picture of Hap particles obtained from solutions with $\mathrm{R}=3$ and $\mathrm{pH}=8.12$ aged at $37^{\circ} \mathrm{C}$ for $24 \mathrm{~h}$; SEM picture of Hap particles obtained from solutions with $\mathrm{R}=5$ and $\mathrm{pH}=8,15, \mathrm{pH}=$ 8,52 and $\mathrm{pH}=8,62$
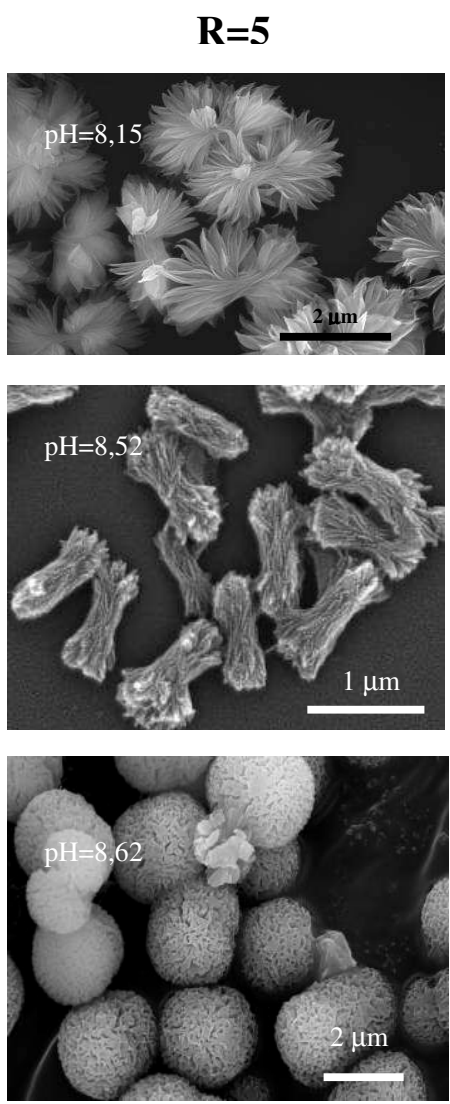
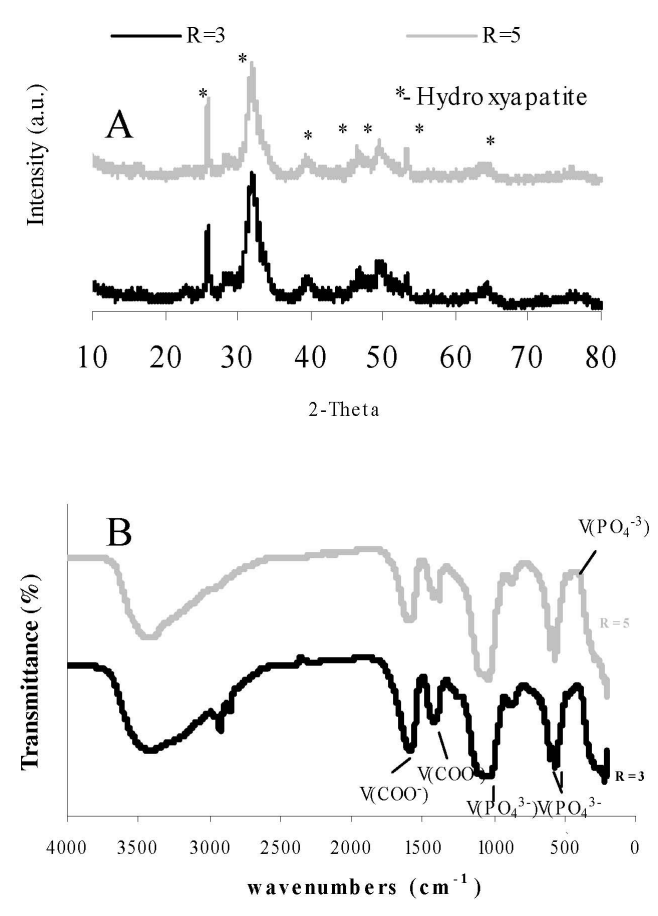

Fig 2. XRD diffraction patterns (A) and FTIR spectra (B) of the powders precipitated in solutions with: $(-) \mathrm{R}=3(\mathrm{pH}=8,12)$ and $(-)$ $\mathrm{R}=5(\mathrm{pH}=8,15)$.

\begin{tabular}{|ccc|}
\hline $\begin{array}{c}\text { Solution } \\
\text { ratio }\end{array}$ & $\begin{array}{c}\text { pH } \\
\text { solution }\end{array}$ & $\begin{array}{c}\text { Morphology } \\
\text { shape }\end{array}$ \\
\hline \hline 3 & $8,12 \pm 0,02$ & needles \\
\hline 5 & $8,15 \pm 0,02$ & Flower \\
\hline 5 & $8,52 \pm 0,02$ & Bundle \\
\hline 5 & $8,62 \pm 0,02$ & spherical \\
\hline
\end{tabular}

Table1-Experimental conditions used for particles precipitation 